\title{
Exhaustivity in Focus: Experimental Evidence from Hungarian
}

\author{
Mátyás Gerőcs ${ }^{a}$, Anna Babarczy ${ }^{b}$, and Balázs Surányic \\ a, b, cResearch Institute for Linguistics of the Hungarian Academy of Sciences, Hungary \\ 'Pázmány Péter Catholic University, Hungary \\ agerocs.matyas@nytud.mta.hu, bbabarczy.anna@nytud.mta.hu, csuranyi@nytud.hu
}

\begin{abstract}
This study presents the results of two experiments investigating the nature of exhaustivity of pre-verbal focus in Hungarian, both doing so in an indirect way. Experiment 1 contrasts the responses given in long versus short time windows in a truth-value judgment task. Experiment 2 makes the task itself indirect and compares pre-verbal focus with three other types of focus in the same language. Through these multiple comparisons we provide evidence that exhaustivity in pre-verbal focus is not entailed, unlike exhaustivity in clefts, with which it has been treated as being on a par. Instead, it is due to pragmatic implicature, in particular, conventional implicature.
\end{abstract}

Keywords: focus; exhaustivity; implicature; experimental pragmatics; Hungarian

\section{Introduction}

One of the characteristic interpretive properties of focus is its exhaustivity, whose nature has become a controversial issue in the semantic and pragmatic literature in recent years. In Rooth's $(1985,1992)$ classic account the function of focusing is to indicate the presence of alternatives relevant to the interpretation of a certain linguistic expression.

\section{(1) (a) Who did Walter invite? \\ (b) Walter invited $[\text { Mickey }]_{\mathrm{Foc}}$.}

A possible set of alternatives to [Mickey] would be a set consisting of other individuals Walter could have invited, e.g., \{Donald, Goofy, Daisy\}. Focus is interpreted exhaustively if the predicate conveyed by the background is taken to hold for no other focus alternatives than the one denoted by the focused element. Thus, under an exhaustive reading of (1b) the set of individuals Walter invited consists of Mickey and no one else.

Exhaustivity of focus has been most commonly treated as a conversational implicature that can be derived either from Grice's Maxim of Quantity or in terms of Relevance in Relevance Theoretic accounts. Some theorists, however, have proposed that exhaustivity cannot exclusively be regarded as a purely pragmatic phenomenon. É. Kiss (1998) argues that two types of focus should be distinguished cross-linguistically: information focus and identificational focus. These two types differ substantially with respect to the status of the exhaustivity effect associated with them. While the function of information focus is to mark new, non-presupposed information (and indeed, can be interpreted exhaustively as a result of pragmatic inferences), identificational focus involves identificational predication as part of its semantics. Functioning as an identificational 
predicate akin to specificational predicates in specificational copular sentences (Higgins 1979), identificational focus exhaustively identifies the set of individuals of which the predicate corresponding to the background of the focus holds, implying that exhaustivity is part of its meaning.

An oft-cited example of this latter, identificational type of focus is Hungarian Pre-verbal Focus (PVF). According to the standard analysis (Szabolcsi 1981; É. Kiss 1987; Kenesei 1986; Szabolcsi 1994), PVF involves truth-conditional, semantically encoded exhaustivity (unlike its syntactically unmarked counterpart) and has a semantic representation similar to that of English it-clefts. During the last decade, this view of PVF has been both challenged (Wedgwood 2005, 2007) and defended (É. Kiss 2006, 2010; Horváth 2005, 2007) in theoretical work. Recent experimental results (Onea and Beaver 2011; Kas and Lukács 2013) suggest that the exhaustivity of PVF is less robust than would be expected if it were a semantic feature of PVF.

The present paper reports on two experiments investigating the interpretation of different focus constructions in Hungarian, including PVF, and aims to provide further evidence in the debate concerning the semantic vs. pragmatic nature of the exhaustivity of focus.

\section{Focus Marking in Hungarian and the Semantics vs. Pragmatics Debate}

Hungarian, like English, can mark focus purely prosodically, without syntactic reordering: the focused element (which can occur anywhere within the post-verbal field) can be highlighted simply by prosodic prominence (É. Kiss 1998):
(a) Kit hívott fel János?
who.ACC called up John
"Who did John call?"
(b) János felhívta [MARIT].
John up.called Mary.ACC
"John called Mary."

In addition to being marked by prosodic means, focus can also be marked syntactically. In the syntactically marked case the focused constituent leaves its base position and moves to a designated position (often referred to as "focus position") immediately preceding the tensed verb:
(3)
(a) Kit hívott fel János? who.ACC called up John "Who did John call?"
(b) János [MARIT $]_{\mathrm{Foc}}$ hívta fel. John Mary.ACC called up "John called Mary."

The movement of focus into the pre-verbal region is also indicated by the post-verbal occurrence of the verbal particle $(f e l)$, which in neutral (non-focused) sentences precedes the verb.

Both types of focus, (2b) and (3b), can be assigned an exhaustive interpretation; however, the way the exhaustive reading arises in the two constructions has been claimed to be different. The typology proposed by É. Kiss (1998) considers pre-verbal focus (PVF) an instance of 
identificational focus, whose exhaustivity is a semantic consequence of its identificational function. By contrast, syntactically unmarked focus (SUF) is classified as an instance of information focus, whose exhaustivity is regarded as being due to an implicature that can be derived from pragmatic principles, such as Grice's conversational maxims. In terms of the Maxim of Quantity, hearers normally assume that the speaker has provided all the relevant information, taking the answer in ( $2 \mathrm{~b}$ ) to be maximally informative, i.e., they conclude that no one else beside Mary was called, as otherwise the speaker would have said so.

The exhaustivity of the PVF construction has been considered to be part of its truth conditions. Among other evidence, examples like (4) have been cited to support this claim (Szabolcsi 1981):

(4) Nem $[\text { PÉTER }]_{\text {Foc }}$ aludt a padlón, hanem $[\text { PÉTER ÉS PÁL }]_{\text {Foc }}$.
not PETER slept the floor-on but PETER AND PAUL
"It is not Peter who slept on the floor, but Peter and Paul."

The reasoning here is that the exclusion of the alternatives to the focused expressions ([Péter] and [Péter and Paul], respectively) must be taken to be part of the truth conditions of each clause, as otherwise their conjunction would result in a logical contradiction. The conventional semantic approach is that truth-conditional meaning must be derived compositionally by the grammar (implying that pragmatically inferred meaning cannot be truth-conditional). Accordingly, traditional analyses of PVF assume an abstract semantic operator (dubbed an exhaustivity, identificational, or maximality operator) to be associated with the pre-verbal position, and argue that this operator is responsible for triggering the exhaustivity effect. In essence, the PVF construction has been claimed to presuppose the existence of a unique maximal entity with the property represented by the background material. The assertion that is made is that this presupposed entity is identical to the denotation of the focused constituent. Thus, on this view exhaustivity is actually an entailment of the presupposed and asserted content taken together. (5) represents the meaning of focus in (3b):

$$
\exists x[\operatorname{called}(j, y) \& \forall y[\operatorname{called}(j, y) \rightarrow y \subseteq x] \& x=\text { Mary }]
$$

Focus constructions in other languages have also been claimed to involve semantically identificational focus, including Catalan (Vallduví and Vilkuna 1995), Greek (Tsimpli 1994), and Finnish (Vilkuna 1994), among others.

This type of semantic analysis has been challenged by Wedgwood $(2005,2007)$ and Onea (2007, 2009). Wedgwood argues that there is no basis for the assumption that inferential processes cannot influence truth-conditional meaning, and nothing prevents exhaustivity from being derived from pragmatic factors (as it is in the case of SUF). Wedgwood himself prefers the relevance theoretic account of the exclusion of alternatives. He proposes that in any situation where the utterance is the result of a choice from mutually manifest alternatives (generated by focusing), the exhaustive interpretation is the optimally relevant one, i.e., generating the quantity implicature is worth the cognitive effort.

Some recent experimental studies have also argued that exhaustivity is not an inherent semantic feature of PVF. Onea and Beaver (2011) report on the results obtained from an innovative implementation of a truth value judgment task designed to investigate the issue. Their participants were 
shown pictures in which two persons (e.g., Mark and Bill) were involved in an event, e.g., they both caught a butterfly. Then the participants heard a one-sentence description of the event of the type Mark caught a butterfly with the role of Mark as a focus varied (PVF or neutral), and had to choose from three possible response options: Yes, and Bill did too; Yes, but Bill did too; and No, Bill did too. The authors used only-focus as a baseline comparison (Only Mark caught a butterfly) and hypothesized that if PVF is indeed semantically exhaustive, then the response pattern of the two focus constructions would be similar. This was, however, not what they found: while only-focus sentences were rejected most of the time, PVF sentences were accepted (i.e., responded to with one of the two Yes, ... replies) relatively willingly (71\%) as descriptions of non-exhaustive situations ${ }^{1}$ (see also Kas and Lukács [2013] for comparable results). ${ }^{2}$

Though the authors interpret the results as supporting the pragmatic analysis of exhaustivity, basing this conclusion on the difference found between PVF and only-focus is rather questionable. While only-focus asserts exhaustivity (Horn 1981, 2002), in the case of PVF it is claimed to be part of the presupposition:

$\begin{array}{llll}\text { (a) Csak } & \text { Mari } & \text { ment } & \text { el. } \\ \text { only } & \text { Mary } & \text { left } & \text { PRT }\end{array}$

Presupposition: Mary left. Assertion: Nobody other than Mary left.

(b) $[\mathrm{MARI}]_{\mathrm{Foc}}$ ment el.

Mary left PRT

Presupposition: There is a unique/maximal individual who left. Assertion: It is Mary.

The difference between the two is indicated, among others, by the fact that exhaustiveness is accessible to negation in only-focus sentences, but not in PVF ones. As the contrast in the acceptability of the but-clause continuation in (7) shows, exhaustivity can be negated in the only-focus sentence (7a), unlike in the PVF sentence (7b).

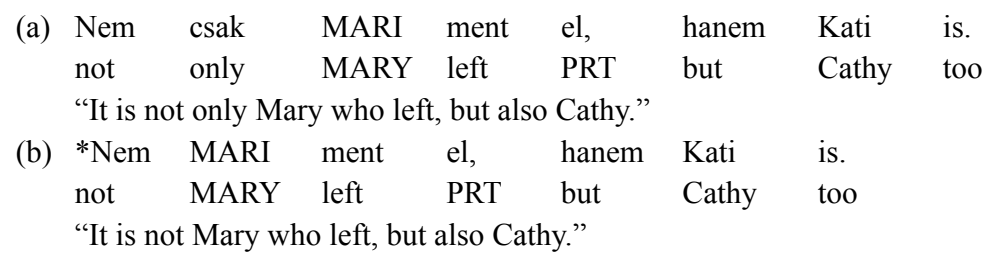

The fact that Onea and Beaver (2011) base their conclusion on results obtained from a forced choice among the No, . . ; the Yes, but . . ; and the Yes, and . . responses also gives cause for

1 Onea and Beaver's (2011) first experiment had a low number of test sentences and participants. It was repeated with a wh-question preceding the test sentences and with a larger number of participants, but no statistical analysis was provided.

2 Kas and Lukács's (2013) very recent series of experiments confirm Onea and Beaver's (2011) results and extend their work by exploring the exhaustivity of PVF with various syntactic functions in the pre-verbal focus position. 
concern, since it is not established independently what that choice is conditioned by. Hearers may (or may not) express disagreement with different aspects of sentence interpretation, including asserted content, non-asserted entailments, presuppositions, conversational implicatures, etc. Before it is established which type of response is given if one of these aspects of sentence meaning or another is not accepted by the hearer, it is difficult to draw any firm conclusions from the relative proportions of these responses.

Although Onea and Beaver's experiment is a major step toward an appropriate empirical assessment of the theoretical accounts reviewed above, the results remain inconclusive. Compelling empirical evidence that would address the nature of the exhaustivity effect of PVF is still lacking.

It is this gap that the present study attempts to fill through two experiments. Experiment 1 is an online two-valued truth-value judgment task where a context (set of alternatives) is specified and the response time window is manipulated. Experiment 2 is an offline task embedded in a natural setting, where participants are asked to match pictures to sentences, thus avoiding reliance on metacognitive truth-value judgments. In Experiment 2 the only-focus condition is reexamined and a cleft condition is introduced for comparison.

\section{Experiment 1}

The experiment involved a truth-value judgment task based on a method in Bott and Noveck's (2004) investigation of scalar implicatures. The method builds on the prediction of Relevance Theory that, keeping the attainable contextual effect constant, the probability of a pragmatic implicature decreases when its processing cost would be too high for the available cognitive resources. That is, when cognitive resources are limited, we expect listeners to process semantic content but not pragmatic implicatures. We therefore predict that if the exhaustivity of PVF is indeed a pragmatic phenomenon, the probability of the implicature being processed should decrease under the above conditions. If, on the other hand, exhaustivity is a semantic feature, it should be processed regardless of the availability of extra cognitive resources.

\subsection{Participants}

Sixty undergraduates studying at the Budapest University of Technology, all native speakers of Hungarian with unimpaired hearing, participated in the experiment. The students participated on a voluntary basis and received course credit for their participation.

\subsection{Materials}

Digital recordings were used of a context story followed by a question, uttered by one speaker, and an answer, uttered by a different speaker. The question was a wh-question querying the object affected by the event described in the context story, realized as a grammatical object in all critical conditions. The structure of the context story and the question was identical for all test items. The answer gave a full answer to the question. There were two answer conditions (sentence types): PVF and SUF. An example is shown below in English translation:

\subsection{Context}

This morning the maid found a corpse in one of the apartments of the Hotel Royale. In the pocket of the victim there was a crumpled piece of paper. There were three figures on it: a crown, a fish, and a pyramid. The victim had circled one or more of them. 
Question: What had the victim circled?

$\begin{array}{lllllll}\text { Answer (PVF): } & \text { Az } & \text { áldozat a PIRAMIST } & \text { karikázta } & \text { be. } \\ & \text { the } & \text { victim } & \text { the PYRAMID.ACC circled } & \text { PRT } \\ \text { Answer (SUF): } & \text { Az } & \text { áldozat } & \text { bekarikázta a } & \text { piramist. } & \\ & \text { the } & \text { victim } & \text { circled } & \text { the pyramid.ACC } & \end{array}$

For each item there was a picture depicting what happened in reality. In all critical conditions the picture depicted a non-exhaustive interpretation of the target sentence (e.g., a piece of paper with a crown, a fish, and a pyramid drawn on it and red circles around the pyramid and the crown).

There were six test items and twelve fillers. The filler items had the same structure as the test items but half of the pictures depicted the exhaustive interpretation and the other half depicted a scene where the object of the event did not match the object mentioned in the answer to the question.

\subsection{Design and Procedure}

The experiment was run on E-prime. The participants sat in front of a computer screen with headphones on. They listened to the recordings of the context story, the question and the target sentence. At the onset of the target sentence, a picture appeared on the screen. The participants had to press a green button on the keyboard if the picture matched the sentence and a red button if the picture did not match the sentence. Thus, for the test items, a yes response indicated acceptance of the non-exhaustive interpretation, while a no response indicated a preference for exhaustive interpretation. Reaction time was measured from the offset of the noun in the target sentence. There were two lists; thus each participant heard each context only once but the items were counterbalanced, giving a within-subject design for sentence type.

A second variable of the experiment was cognitive resource. The participants were divided into two groups. One group was told to give their response before they heard a beep. The beep was played $1000 \mathrm{~ms}$ after the offset of the noun in the target sentence. The experimental session began with six practice trials, in which participants were able to get used to the time constraint. This was sufficient practice as all of the experimental trials were successful. The other group were not given a time limit but were told to reply as quickly as possible. For the sake of uniformity, a beep at $3000 \mathrm{~ms}$ after the offset of the noun was built into the experiment for this group.

\subsection{Results}

As the test items allowed both yes and no responses, depending on the participants' interpretation of the sentences, the fillers were used to measure accuracy and the effects of the time constraint on accuracy. Half of the fillers unambiguously required a yes response and the other half a no response. On the basis of filler accuracy, three outliers were excluded from the Long Group and one from the Short Group. For the remaining 56 respondents, filler accuracy and mean reaction times for the time limited (Short) and the unlimited (Long) Groups are shown in Table 1. RT was measured from the offset of the noun in the target sentence. 


\begin{tabular}{lcc} 
& Long Condition & Short Condition \\
\hline Filler accuracy & $93 \%$ & $91 \%$ \\
Mean RT fillers & $1752 \mathrm{~ms}$ & $320 \mathrm{~ms}$ \\
Mean RT test items & $3597 \mathrm{~ms}$ & $437 \mathrm{~ms}$ \\
\hline
\end{tabular}

Table 1. Accuracy and mean RT for filler items in the Long and the Short experimental conditions.

Although 91\% accuracy is not perfect, it is evident from the figures in Table 1 that the time constraint is not responsible for the errors, as the accuracy rates in the Short and the Long Conditions are almost identical. We can therefore contend that the available response time window in the Short Condition did not interfere with the processing of the semantic content of the target sentences.

Table 1 also reveals that the participants in the Short Group understood and respected the instructions, while the participants in the Long Group took their time giving their responses. For both groups, but especially for the Long Group, longer response times were needed for the test items than for the fillers. Although they are not shown in the table, there were considerable differences in reaction times between the PVF and SUF sentence types (4239 vs. 2956 $\mathrm{ms}$ in the Long Condition and 597 vs. $278 \mathrm{~ms}$ in the Short Condition). This is not surprising, since RT was measured from the offset of the noun, which necessarily appeared pre-verbally in the PVF sentences and post-verbally in the SUF sentences. This circumstance is of no consequence, however, as we are interested in differences in response types rather than in reaction times between the two sentence types.

The percentages of exhaustive interpretations (no responses) for the two sentence types in the two time window conditions are shown in Figure 1.

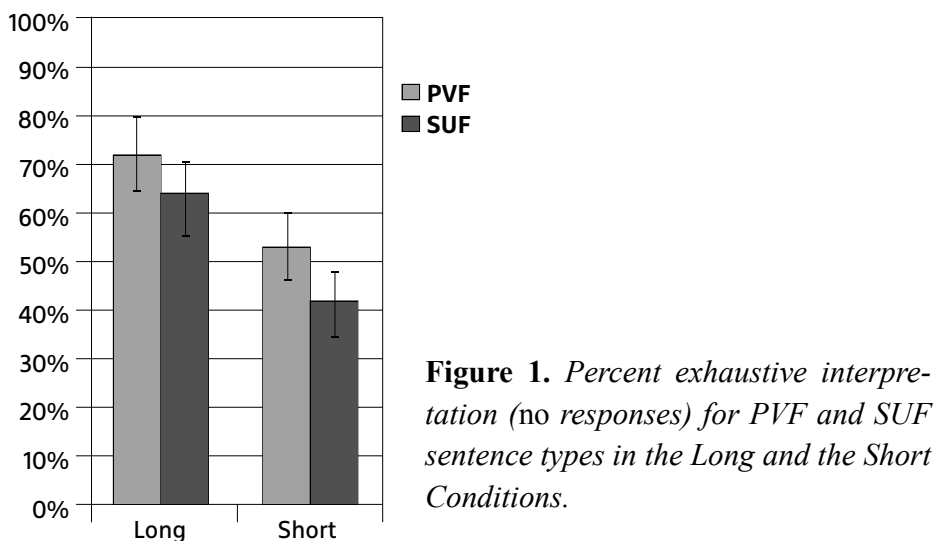

A Sentence Type by Response Time Window ANOVA reveals no main effect of Sentence Type but a highly significant main effect of Response Time Window $(F(1,54)=73.8, p<.001)$ with no interaction. That is, although SUF sentences are slightly less likely to be interpreted exhaustively (63\% in Long Condition and $41 \%$ in Short Condition) than PVF sentences (72\% in Long Condition and 53\% in Short Condition), the difference between the two is not statistically significant. 


\section{Discussion of Experiment 1}

In Experiment 1 we tested whether in a TVJ task limiting the time to respond (and thereby increasing the computational cost of inferences) had any effect on the interpretation of PVF in comparison to SUF, whose exhaustivity is undoubtedly pragmatic. We predicted that if PVF is semantically exhaustive then such a manipulation would not affect its exhaustivity rating. However, if it is pragmatically exhaustive, then it would pattern with SUF, i.e., it would give rise to significantly less exhaustive interpretations in the Short Condition than in the Long Condition. When the participants had a long time window to respond, we found that SUF sentences were interpreted exhaustively to the same degree as PVF sentences, which can be attributed to the effect of the preceding $w h$-question that served as a trigger for implicature generation. Limiting the response time, however, caused a significant drop in the proportion of exhaustive responses to both PVF and SUF sentences.

The results obtained in Experiment 1 allow for at least two interpretations. (i) The decrease in the proportion of exhaustive responses from the Long to the Short Condition can be explained as a consequence of a speed-accuracy trade-off. The 1000-ms time limit we imposed might have been too short to process the sentences even semantically and it made the participants perform at chance level. The analysis of individual participant data reveals that the rate of inconsistent responses within subjects was much higher in the Short Condition, which also supports this option.

On the other hand, (ii) the increased rate of non-exhaustive responses and individual inconsistency in the Short Condition can also be due to the implicature status of exhaustivity in PVF. It was predicted that the time pressure would make the exhaustivity inference less likely to emerge, since, as an implicature, it is less likely to be processed when cognitive resources are scarce. As predicted, an exhaustive interpretation occurred less frequently in the responses. The lack of a significant difference between PVF and SUF within either the Long or the Short Condition is also expected, assuming that exhaustivity is caused by the same pragmatic mechanisms in both sentences with pre-verbal focus and sentences with the noun phrase in a post-verbal position. This latter interpretation of the results is supported by the fact that the subjects did relatively well on the filler trials, and that most of the time they did not use up their one-second time lag.

If so, then the exhaustivity of PVF is not truth-conditional, but an implicature sensitive to extra-grammatical factors. In order to test this conclusion further, we conducted a second experiment.

\section{Experiment 2}

Experiment 2 was designed to avoid participants having to make direct truth-value judgments and to test the effects of abandoning the question preceding the target sentence, which naturally invited an implicature of exhaustivity in Experiment 1. A further aim of Experiment 2 was to explore the interpretation of PVF in comparison with cleft constructions, also including SUF and only-focus, as expected limiting cases. The latter three types of sentence exemplify semantically entailed exhaustivity in the sense of Percus (1997; cleft), asserted exhaustivity in the sense of Horn (1981, 2002; only-focus), and pragmatic exhaustivity (SUF). The first two types are expected to show a strong preference for exhaustive interpretation. SUF is expected to be far less likely to be interpreted exhaustively, since there is no context (wh-question) encouraging that interpretation. Assuming that clefts are semantically exhaustive, if PVF is 
semantically exhaustive in the same way, then the rate of exhaustive interpretations of PVF sentences should not differ significantly from that of cleft sentences.

\subsection{Participants}

Forty-two undergraduates participated in the experiment, none of whom participated in Experiment 1. All the participants were native speakers of Hungarian. The students participated on a voluntary basis and received course credits for their time.

\subsection{Materials}

Each test item had four versions: a PVF, a SUF, an only-focus, and a cleft version. All the items consisted of a single sentence describing an event that affected the appearance of an individual. The individual was the subject of the sentence and the object of the event appeared in various focus positions, as in (8a)-(8d) below.
(a) A KALAPOT próbálta fel. the HAT.ACC tried.he on "He tried on the HAT."
(b) Felpróbálta a kalapot. on.tried.he the hat.ACC "He tried on the hat."
(c) Csak a kalapot próbálta fel. only the hat.ACC tried.he on "He only tried on the hat."
(d) A kalap volt az, amit felpróbált. the hat was it that on.tried.he "It was the hat that he tried on."

For each test sentence there were four pictures: one depicting the exhaustive interpretation of the sentence (e.g., a man wearing just a hat); one depicting a non-exhaustive interpretation (e.g., a man wearing a hat and a scarf), and two distractors (e.g., a man wearing sunglasses or a bow tie but no hat).

There were five different test items and ten fillers. Each filler had four different versions with variations in either lexical items or word order. The pictures paired with the filler items either unambiguously matched or unambiguously mismatched the filler sentence.

\subsection{Design and Procedure}

The experiment was run on E-prime. The participants were seated by a computer and introduced to a story in which the police were looking for a thief. The participant was to read eye-witness descriptions of the thief at the top of the computer screen and at the same time see pictures of four individuals in a single row below the description. The pictures were numbered 1 to 4 . An input box was visible at the bottom of the screen and the participants were asked to use the keyboard to type the number(s) of the picture(s) that depicted an individual who could possibly be the thief on the basis of the eye-witness description. They were told that they could choose one or more of the pictures. 
Every participant read every sentence in the experiment. The sentences appeared in a pseudorandomized order that did not allow any two versions of the same item to follow each other immediately. The four pictures within each set appeared in random order.

\subsection{Results}

The responses to the test items were evaluated as follows: if only the picture depicting the exhaustive interpretation of the target sentence was chosen, the response was classed as exhaustive. If both the picture depicting the exhaustive interpretation and the picture depicting a non-exhaustive interpretation were chosen, the response was classed as non-exhaustive. In any other case, the response was classed as incorrect. On the basis of this classification, the overall accuracy rate was $98 \%$. None of the participants and none of the items had to be excluded from the analysis.

The percentages of exhaustive responses for the four sentence types are shown in Figure 2.

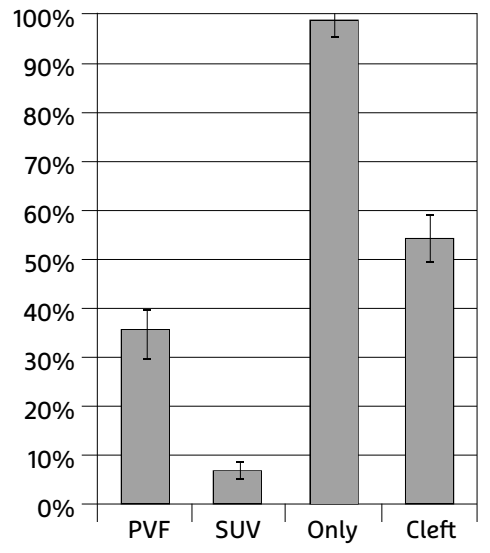

Figure 2. Percentages of exhaustive responses for Pre-verbal Focus, Syntactically Unmarked Focus, Only-Focus, and Cleft Sentence Types.

A Friedman ANOVA revealed a significant difference between the four Sentence Types (Chi2 = $110.14, \mathrm{df}=3, p<.001)$. Pairwise comparisons show significant differences between any two conditions in the expected direction: only-focus was the most likely to be interpreted exhaustively (almost without exception, 98\%) while SUF hardly ever received an exhaustive interpretation (7\%). PVF (35\%) and cleft (54\%) sentences fell in between the two extremes.

\section{Discussion of Experiment 2}

In Experiment 2 we introduced two more focus types, cleft and only-focus, in order to cover all three levels of meaning (assertion, semantic inference, and implicature) exhaustivity can possibly arise at. Since only asserts the exclusion of alternatives, the frequency of exhaustive responses to the only-focus sentences was expected to be very high. On the basis that clefts are standardly analyzed as being identificational predicates (with exhaustivity being a joint entailment of the maximality presupposition and the assertion), we assumed that if PVF is semantically exhaustive, then its exhaustivity profile would be similar to that of clefts (with which they have been claimed to be semantically synonymous) and would differ significantly from that of SUF. This time we had no $w h$-questions preceding the target sentences that would lead to the 
constant contextual effect of triggering the exhaustivity implicature. We also wanted to avoid having the participants make judgments about truth, so we used a special sentence-picture matching task that enabled us to tap into speakers' interpretation of focus sentences in a more indirect way.

As expected, we found that the only-focus sentences were interpreted exhaustively virtually without any exception. The rate of exhaustivity in the clefts was relatively high but still lower than that of only-focus, which is reasonable given the fact that in the case of clefts exhaustivity is entailed and not asserted. As opposed to Experiment 1, the rate of exhaustive responses to the SUF sentences was very low, which can be attributed to the removal of the wh-question: the Q-implicature (responsible for exhaustive interpretation) simply did not arise in the absence of an explicit indicator of its relevance. Regarding the PVFs, they were interpreted exhaustively significantly less frequently than the clefts. This is unexpected if exhaustivity is a semantic entailment both in clefts and in PVF (as has been claimed by semantic approaches to PVF exhaustivity), while it is explained if exhaustivity in PVF sentences is due to an implicature.

Although a direct comparison of the values of PVF exhaustivity obtained in the two experiments is strictly speaking not possible, such a comparison, in view of the numerically large differences, is still suggestive. Notably, the frequency of exhaustive interpretations of PVF is less than half (35\%) in Experiment 2 of what it is in Experiment 1 in the Long Condition (72\%). Recall that the key difference between the two settings lay only in the presence of the $w h$-question preceding the target sentence. This striking difference also supports the view that exhaustivity in PVF sentences is due to a conversational implicature, rather than arising from an entailment, assuming that entailments of a sentence should be relatively stable and independent of the preceding context (or a lack thereof) in the relevant sense.

On the other hand, the PVF sentences gave rise to significantly more exhaustive interpretations than the SUF sentences, which makes the latter conclusion somewhat controversial. One way to resolve this is to assume that there is a pragmatic difference between the two: the exhaustivity implicature is less dissociable from PVF sentences than from SUF sentences, because the marked PVF word order itself flags the pre-verbal element as information focus, i.e., as the answer to the Question under Discussion (QUD; Roberts 1998). Here we follow Onea (2009) and Onea and Beaver (2011), who argue that the immediately pre-verbal position in Hungarian grammatically marks a question-answering constituent. Thus, pre-verbal foci in Hungarian will be interpreted as answering an accommodated information question even in isolation from the context (including the question itself). Given the pragmatic tendency to interpret answers as adequate for the conversational goals at hand (i.e., as complete or maximally informative), the exhaustivity effect of PVF can be accounted for. As the implicature is associated with the particular form (here: the word order in focus fronting with verb inversion), we contend that it is more appropriate to consider the exhaustivity of PVF to be a conventional implicature than a conversational implicature.

\section{Conclusion}

The study presented the results of two experiments investigating the nature of exhaustivity of PVF in an indirect way: Experiment 1 contrasted responses given in long versus short time windows in a truth-value judgment task, while Experiment 2 involved an indirect task and compared PVF with three other types of focus. Through these multiple comparisons we have provided evidence 
that in PVF exhaustivity is not entailed, unlike exhaustivity in clefts, with which it has been treated on a par, but it is due to pragmatic implicature. In particular, we have suggested that it is to be analyzed as a conventional implicature. Our results can potentially provide a stronger argument against assigning exhaustivity a truth-conditional semantic status in PVF than previous empirical investigations of the issue precisely on account of the comparisons made, situating the rate of PVF's exhaustive interpretations in relation to other relevant focus types, most importantly, SUF and the cleft construction, as well as comparing this rate in an (quasi) offline task with the same rate in a speeded judgment task setting.

We believe that the investigations reported on here go beyond the issue of PVF and have broader relevance, on at least two counts. On the methodological side, they highlight the value of, and need for, comparisons with multiple focus types in experiments that seek to reveal the nature of the exhaustivity effect of a particular focus construction in a language. The landscape of exhaustivity is more nuanced than simply truth-conditional semantics versus pragmatic implicature. As Experiment 2 demonstrated, the level of exhaustivity depends on whether exhaustivity is asserted or entailed, and on the other hand, it is affected by the extent to which contextual triggers of exhaustivity may themselves be grammaticalized in a particular focus construction.

A second general repercussion concerns Q-implicatures. If exhaustivity in PVF is due to a pragmatic implicature, the view we have presented strong evidence for, then the striking difference in the exhaustivity rates of PVF in Experiment 1 and Experiment 2, associated with the presence versus absence of an explicit question in the immediate context, supports contextualist approaches to Q-implicatures (e.g., Wilson and Sperber 2004; van Rooij 2002; as opposed to defaultist views), according to which implicatures licensed by a sentence arise as a function of context.

\section{Funding Acknowledgement}

The authors of this work were supported by the Momentum grant of the Hungarian Academy of Sciences, and by grant no. 84217 of the Hungarian Scientific Research Fund.

\section{Works Cited}

Bott, Lewis, and Ira A. Noveck. 2004. "Some Utterances Are Underinformative: The Onset and Time Course of Scalar Inferences.” Journal of Memory and Language 51: 437-57.

É. Kiss, Katalin. 1987. Configurationality in Hungarian. Dordrecht: Reidel.

É. Kiss, Katalin. 1998. “Identificational Focus versus Information Focus.” Language 74: 245-73.

É. Kiss, Katalin. 2006. “Focusing as Predication.” In The Architecture of Focus, edited by Valéria Molnár and Susanne Winkler, 169-96. Berlin: Mouton de Gruyter.

É. Kiss, Katalin. 2010. "Structural Focus and Exhaustivity." In Information Structure: Theoretical, Typological and Experimental Perspectives, edited by Malte Zimmermann and Caroline Féry, 64-88. Oxford: Oxford University Press.

Higgins, Francis Roger. 1979. The Pseudo-cleft Construction in English. New York: Garland. Horn, Laurence. 1981. "Exhaustiveness and the Semantics of Clefts." In NELS 11: Proceedings of the 11th Annual Meeting of the North Eastern Linguistic Society, edited by Victoria E. Burke and James Pustejovsky, 125-42. Amherst: University of Massachusetts.

Horn, Laurence. 2002. "Assertoric Inertia and NPI Licensing." CLS 38: Proceedings from the 38th Meeting of the Chicago Linguistic Society, vol. 2, The Panels, edited by Mary Adronis, 58-82. Chicago: Chicago Linguistic Society. 
Horváth, Julia. 2005. “Is 'Focus Movement' Driven by Stress?” In Approaches to Hungarian: Papers from the Düsseldorf Conference, edited by Christopher Piñón and Péter Siptár, 131-58. Budapest: Akadémiai Kiadó.

Horváth, Julia. 2007. "Separating 'Focus Movement' from Focus." In Phrasal and Clausal Architecture: Syntactic Derivation and Interpretation, edited by Simin Karimi, Vida Samiian, and Wendy Wilkins, 108-45. Amsterdam: John Benjamins.

Kas, Bence, and Ágnes Lukács. 2013. "Focus Sensitivity in Hungarian Adults and Children." Acta Linguistica Hungarica 60 (2): 217-45.

Kenesei, István. 1986. “On the Logic of Word Order in Hungarian.” In Topic, Focus and Configurationality: Papers from the 6th Groningen Grammar Talks, edited by Werner Abraham and Sjaak de Mey, 143-59. Amsterdam: John Benjamins.

Onea, Edgar. 2007. "Exhaustivity, Focus and Incorporation in Hungarian." In Proceedings of the Sixteenth Amsterdam Colloquium, edited by M. Aloni, P. Dekker, and F. Roelofsen, 169-174. Amsterdam: ILLC/Department of Philosophy, University of Amsterdam.

Onea, Edgar. 2009. "The Myth of Hungarian Focus.” In: Current Issues in Unity and Diversity of Languages: Collection of the Papers Selected from the CIL 18, n.p. Seoul: Linguistic Society of Korea.

Onea, Edgar, and David Beaver. 2011. "Hungarian Focus Is Not Exhausted." In Proceedings of the 19th Semantics and Linguistic Theory Conference: SALT 19, edited by Satoshi Ito Cormany and David Lutz, 342-59. Ithaca: Cornell University.

Percus, Orin. 1997. "Prying Open the Cleft." In Proceedings of the North East Linguistic Society 27: NELS 27, edited by Kiyomi Kusumoto, 337-51. Amherst: GLSA.

Roberts, Craige 1998. "Focus, the Flow of Information and Universal Grammar." In The Limits of Syntax, edited by Peter W. Culicover and Louise McNally, 109-60. San Diego: Academic Press.

Rooth, Mats. 1985. “Association with Focus.” PhD diss., University of Massachusetts, Amherst.

Rooth, Mats. 1992. “A Theory of Focus Interpretation.” Natural Language Semantics 1 (1): 75-116.

Szabolcsi, Anna. 1981. "The Semantics of Topic-Focus Articulation." In Formal Methods in the Study of Language, edited by J. A. G. Groenendijk, T. M. V. Janssen, and M. J. B. Stokhof. Amsterdam: Mathematisch Centrum.

Szabolcsi, Anna. 1994. "All Quantifiers Are Not Equal: The Case of Focus.” Acta Linguistica Hungarica 42-43: 171-87.

Tsimpli, Ianthi Maria. 1994. "Focusing in Modern Greek." In Discourse Configurational Languages, edited by Katalin É. Kiss, 176-206. New York: Oxford University Press.

Vallduví, Enric, and Maria Vilkuna. 1995. "Focus and Contrast in Information Structure: Finnish and Catalan.” Paper presented at the Workshop on Finno-Ugric Languages: GLOW 18, Tromsoe, May 31-June 2.

Van Rooij, Robert. 2002. "Relevance Only." In Proceedings of the 6th Workshop on the Semantics and Pragmatics of Dialogue: EDILOG 2002, edited by Johan Bos et al., 155-60. Edinburgh.

Vilkuna, Maria. 1994. "Discourse Configurationality in Finnish." In Discourse Configurational Languages, edited by Katalin É. Kiss, 244-68. New York: Oxford University Press.

Wedgwood, Daniel. 2005. Shifting the Focus: From Static Structures to the Dynamics of Interpretation. Amsterdam: Elsevier. 
Wedgwood, Daniel. 2007. "Identifying Inferences in Focus." In On Information Structure, Meaning and Form: Generalizations across Languages, edited by Kerstin Schwabe and Susanne Winkler, 207-27. Amsterdam: John Benjamins.

Wilson, Deirdre, and Dan Sperber. 2004. "Relevance Theory." In The Handbook of Pragmatics, edited by Laurence R. Horn and Gregory L. Ward, 607-32. Oxford: Blackwell. 